\title{
Increased DNA yield following enzymatic release of Borrelia from a collagen matrix in culture
}

\begin{abstract}
Laboratory culture methods were developed to provide a means of harvesting greater amounts of DNA from Borrelia in culture. Borrelia burgdorferi B31 and Borrelia burgdorferi $\mathrm{N} 40$ were used in the initials experiments to develop optimal conditions. A collagenase enzyme preparation, Liberase TL, was used to release the organisms growing within a collagen matrix embedded in the culture. Optimal conditions of $2 \mathrm{U} / \mathrm{mL}$ of enzyme and 4 minutes of incubation at $37^{\circ} \mathrm{C}$ were obtained. Following the establishment of these parameters, 24 positive patient samples were treated with Liberase and 24 positive patient samples were left untreated. The DNA harvested from both sets was quantified and evaluated for purity. Approximately 3.3-fold more DNA was harvested from the samples treated with Liberase TL than from the untreated samples. A greater degree of DNA purity, with less residual protein remaining, was also achieved.
\end{abstract}

Volume 2 Issue I - 2015

Sheila Wood, Amy Rattelle

Advanced Laboratory Services, Rowan University, USA

Correspondence: Sheila Wood,Advanced Laboratory Services, Rowan University, 50I Elmwood Ave, Sharon Hill, 19079 Pennsylvania, USA, Tel 484494 6I25, Fax 484494 6800, Email swood@advanced-lab.com

Received: March 04, 2015 | Published: March 27, 2015

Keywords: collagen, Borrelia, enzyme

\section{Introduction}

Investigators have shown that the ability of an organism to cause disease in the human often depends on its ability to attach to mammalian cells. Borrelia burgdorferi, the primary cause of Lyme Borreliosis in humans is no exception to this phenomenon. This organism is delivered to the dermis via the bite of the Ixodes scapularis, Amblyomma americanum, or Ixodes pacificus tick. Primarily extracellular and migratory, Borrelia actively moves from the dermis to the bloodstream. Further migration into extracellular matrix $(\mathrm{ECM})$, connective tissue and other tissues of the body, including the heart may occur. ${ }^{1-3}$

Cabello et al., ${ }^{2}$ elucidated factors that influence the establishment of extracellular matrix (ECM) in vivo. ECM is secreted by cells to form an interstitial matrix and basement membrane, which constitute the framework to which cells are anchored. ECM appears to function in the sequestration, storage, and presentation of growth factors and also plays a role in regulation of cell growth, differentiation, and biochemical function. Attachment to and movement along collagen or collagen-containing structures plays an important role in the establishment of Borrelia in the ECM and its sequestration in the

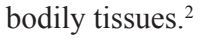

Zambrano et al., ${ }^{1}$ have shown that the binding of Borrelia to collagen in vitro occurred within five minutes of inoculation and the binding increased over time, with maximum binding occurring at 1 hour. Borrelia remained bound to the collagen for 14 days in the presence of BSK-H media both with and without serum. Motile strains invaded collagen matrices on slides and formed micro colonies. Their experiments used collagen acquired from mouse tails that was extracted and solubilized using 3\% acetic acid. The preparation that resulted contained Type I collagen but no decorin or proteoglycans or glycosaminoglycans which were removed using guanidine hydrochloride in Tris-HCl. Following extraction and treatment, the collagen was allowed to reassemble and form a lattice by adjusting the $\mathrm{pH}$ and concentration. Additionally, Borrelia bound to Type I (native) collagen lattices at higher levels than to pepsinized collagen or BSA or gelatin. B. burgdorferi strains MC-1, N40 and B31 showed no variation in their ability to bind type I collagen matrices when collected and used at early, mid or late log phase. On proteinase $\mathrm{K}$ treated surfaces, $B$. burgdorferi showed less adherence, suggesting a role of protein in adherence. Ten percent of the bacterial inoculum still bound collagen after surface treatment with proteinase $\mathrm{K}$.

Our laboratory culture for Borrelia incorporates collagen coated slides as part of the culture process. The presence of a collagen surface within the culture exploits the organism's natural ability to bind to collagen and components within the ECM in vivo as described by Cabello et al. ${ }^{2}$ The matrix allows organisms to attach and form micro colonies. ${ }^{4}$ Although organisms are present upon harvesting, optimal DNA recovery requires the severing of attachment bonds between organisms and collagen. Our objective in this study was to develop a method that would result in the harvesting of an optimal quantity of DNA from organisms growing within the collagen matrix.

The enzyme chosen to release the organisms from the collagen was Liberase TL (Roche). Proteolytic enzymes such as this are commonly used for cell harvesting and tissue dissociation. Proteases are used to disrupt the extracellular matrix of tissue to allow the release of individual cells that are viable and functionally active. (Roche product specification sheet 2010). The collagen coated slide used in the Borrelia culture is coated with Rat Tail Collagen Type I derived from tendon (Corning). The slides are suitable for both serum-containing and serum-free cultures and promote cell attachment, spreading, growth and/or differentiation for a variety of cells. Sapi et al., ${ }^{4}$ used this collagen matrix in culture to harness the natural ability of Borrelia to adhere and form micro colonies.

In our experiments, two strains of Borrelia burgdorferi were used to determine the efficacy of Liberase to improve DNA yield from culture. First, the tick derived B. burgdorferi $\mathrm{B} 31^{5}$ was used to assist in quantifying DNA recovery. $B$. burgdorferi $\mathrm{B} 31$ is a well-documented strain of Borrelia commonly used in laboratory manipulations, and used as a positive control to validate diagnostic tests. It has been described as a strain that has a decreased ability to cause infection. ${ }^{6,7}$ 
The second strain was B. burgdorferi $\mathrm{N} 40$ clone D10/E9. ${ }^{1}$ This strain, also isolated from a tick, harbors a more complete genetic repertoire of plasmids and regulated genes that are involved in the infectious process than B. burgdorferi $\mathrm{B} 31$. It is pathogenic in the mouse model and genetic/adhesion/protein studies show differences from B31 in vitro. ${ }^{7}$ Both were used to assess colonization, and subsequent harvest efficiency, from within the collagen matrix nested in our culture.

Although neither strain of Borrelia showed differences in adherence to Type I collagen in previous experiments, ${ }^{1}$ our approach chose to use both organisms to assess possible differences in attachment to, or release from, our matrix. This study sought to determine if Liberase TL is an appropriate enzyme to release organisms from our collagencontaining cultures and achieve an increase in the yield of DNA. ${ }^{8}$

\section{Materials and methods}

\section{Borrelia culture}

The Borrelia culture media used is described by Sapi et al. ${ }^{4}$ Both $B$. burgdorferi B31 and N40 were maintained separately in this medium and used in these experiments prior to the tenth passage. One group of cultures contained the collagen-coated slides and one group did not contain the slides. Organisms were obtained from the ATCC (B. burgdorferi B31 ATCC \# 35210) ${ }^{9}$ and from Dr John Leong, Tufts University School of Medicine, B. burgdorferi N40 clone D10/E9.

\section{Effects of liberase on DNA yield}

The possible detrimental effects of Liberase on the DNA were tested using B burgdorferi B31. The culture medium with no collagen-coated slide was seeded using $1 \times 10^{6}$ organisms. The culture was allowed to grow for seven days at $34^{\circ} \mathrm{C}, 5 \% \mathrm{CO}_{2}$, and high humidity. The culture was divided into $18,2 \mathrm{~mL}$ micro centrifuge tubes. Cell pellets were obtained by centrifugation. Pellets containing approximately $6 \times 10^{7}$ organisms each, were treated with increasing concentrations $(0.1,0.25,0.50,0.75,1.00,1.25,1.50,1.75$, and 2.0 $\mathrm{U} / \mathrm{mL}$ ) of Liberase TL prepared in sterile distilled water, for eight minutes at $37^{\circ} \mathrm{C}$. Reactions were stopped using a final concentration of $0.1 \mathrm{mM}$ EDTA prepared in PBS. The tubes were then centrifuged at 9,600 $\mathrm{x} g$ for 10 minutes and the supernatant was discarded. DNA was extracted from the organisms remaining in the pellets using the QIAamp Mini Kit (Qiagen Cat \# 51306). DNA concentrations were measured using a Nanodrop 2000. Each treatment condition had a negative control not treated with Liberase TL, but keeping all other conditions the same.

\section{Enzymatic treatment of B. burgdorferi B3I grown in BSK-H containing collagen coated slides}

Previously established culture procedures were used. ${ }^{4} B$. burgdorferi B31 was used at a concentration of $1 \times 10^{6}$ cells to seed culture media. Four Coplin jars, each containing four collagen-coated slides, were seeded and allowed to grow at $34^{\circ} \mathrm{C}$ in $5 \% \mathrm{CO}_{2}$ and high humidity for 28 days. Three collagen-coated slides were removed and treated with Liberase. One slide was used as a control and not treated with Liberase. The concentrations of Liberase TL, used to treat the pellets containing Borrelia attached to collagen, were $0.25,0.50,0.75$, and $1 \mathrm{U} / \mathrm{mL}$. One $\mathrm{mL}$ of each concentration of Liberase was added to each slide and the slides were incubated horizontally at $37^{\circ} \mathrm{C}$ for 1,4 , or 8 minutes. Each slide was washed by tipping, rinsing with $1 \mathrm{~mL}$ PBS collecting run-off, and then pipetting the run-off over the slide repeatedly. The run-off was then collected in a $1.5 \mathrm{~mL}$ micro centrifuge tube and $10 \mu \mathrm{L} 0.1 \mathrm{M}$ EDTA was added to stop enzymatic activity.

\section{Growth of B burgdorferi N40}

B. burgdorferi B31, while used as laboratory control strain, has been described as non-infectious to humans. ${ }^{9}$ Further experiments were conducted using B. Burgdorferi $\mathrm{N} 40$ which has infectious capabilities in mice. ${ }^{5}$ Twelve Coplin jars containing two collagencoated slides and a total volume of $25 \mathrm{~mL}$ each were inoculated with $1 \times 10^{7} \mathrm{~N} 40$ bacterial cells and grown at $34^{\circ} \mathrm{C}$ in $5 \% \mathrm{CO}_{2}$ and high humidity.

\section{Enzymatic treatment of $B$. burgdorferi $\mathbf{N} 40$ pellets harvested from cultures grown for two weeks in BSK-H containing collagen coated slides}

A two-week growth of B. burgdorferi N40 in culture containing the collagen slides was harvested. The slides were scraped and the entire preparation was centrifuged at $9600 \mathrm{x}$ g for 10 minutes Concentrations of $1 \mathrm{U} / \mathrm{mL}$ and $2 \mathrm{U} / \mathrm{mL}$ Liberase TL at 1 minute and 4 minutes, were used to treat the pellets and the reaction was stopped with $0.1 \mathrm{M}$ EDTA.

\section{Purification and analysis of recovered DNA}

Removal of human DNA: Prior to extracting Borrelia DNA from the patient samples, human DNA was removed using the method of Zhou and Pollard. ${ }^{10}$ This method uses Oxgall (5\%) to lyse mammalian cells and Micrococcal nuclease to inactivate mammalian DNA. Controls were performed to ensure that Borrelia DNA would remain intact during this process. Concentrations of Oxgall at $1 \%, 1.5 \%$, $2 \%, 5 \%$, and $10 \%$ in PBS were mixed with B. burgdorferi $\mathrm{N} 40$ at a concentration of $2.6 \times 10^{7}$ cells, incubated at $37^{\circ} \mathrm{C}$ for 10 minutes, and densities were then read in a counting chamber.

DNA purification and measurement: Borrelia DNA was then extracted using magnetic bead technology (MagJet Genomic DNA Kit, ThermoFisherScientific). Following extraction, it was measured using the Nanodrop 2000 at both 260nm (DNA) and 280nm (protein). Ratios of DNA to protein were obtained as a measure of purity. Ratios closer to 2.0 indicate high purity of DNA with little protein content.

\section{Results}

\section{Results of the effects of liberase on DNA yield}

Treatment with Liberase TL for 8 minutes showed detrimental effects on the DNA. The optimal release and thus recovery of DNA occurred at $0.50 \mathrm{U} / \mathrm{mL}$, but other concentrations were ineffective in releasing intact organism DNA. The erratic results emphasized the need to achieve an optimal concentration and time interval when using this enzyme for release of Borrelia from collagen (Figure 1).

\section{Results of enzymatic treatment of B. burgdorferi B3 I grown in BSK-H containing collagen coated slides}

Further attempts to optimize the concentration of Liberase TL and the time of exposure (Table 1), showed very little recovery of DNA when using less than or equal to $1 \mathrm{U} / \mathrm{mL}$. Time periods of 1,4 and 8 minutes and concentrations of $0,0.25,0.50,0.75$ and $1.0 \mathrm{U} / \mathrm{mL}$ were used (Table 2). 


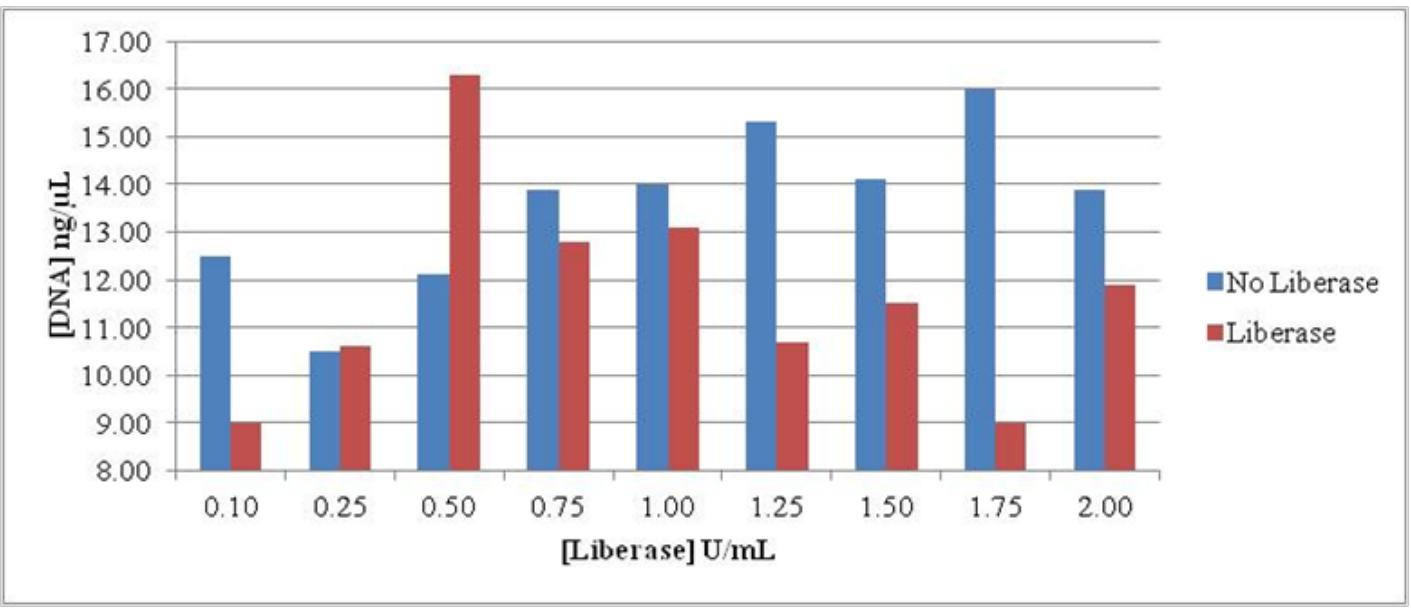

Figure I Intact DNA remaining after treatment of culture pellets containing B burgdorferi B3I. The concentrations of Liberase TL ranged from 0.10 to $2.00 \mathrm{U} /$ $\mathrm{mL}$ Organisms were exposed to Liberase TL for 8 minutes.

Table I Concentrations of Liberase TL and time intervals used

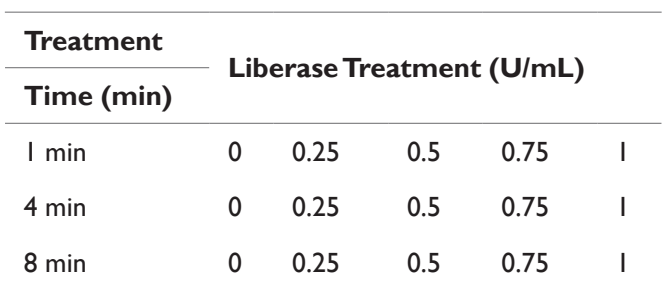

Results of enzymatic treatment of B. burgdorferi N40 pellets harvested from cultures grown for two weeks in BSK-H containing collagen coated slides

An optimal time of 4 minutes incubation at $37^{\circ} \mathrm{C}$ in combination with an optimal concentration of $2 \mathrm{U} / \mathrm{mL}$ Liberase TL gave recovery of $51 \%$ more DNA than the control. As shown in Figure 2, no treatment with Liberase gave DNA levels from 1.4 to $4.8 \mathrm{ng} / \mathrm{uL}$. DNA concentrations obtained after treatment with either 1 or $2 \mathrm{U} /$ $\mathrm{mL}$ Liberase for 1 minute (with scraping) ranged from 7.5 to $10.5 \mathrm{ng} /$ $\mathrm{uL}$. The greatest DNA yield was $20.6 \mathrm{ng} / \mathrm{uL}$ and was obtained after treating culture pellets with $2 \mathrm{U} / \mathrm{mL}$ Liberase for 4 minutes. Liberase treatment of culture pellets plus material and organisms scraped from the collagen coated slides resulted in 51\% more DNA retrieval.

\section{Results of purification and analysis of recovered DNA}

Release of Borrelia from collagen: Using the optimal treatment conditions for release of Borrelia from collagen, 24 patient samples each of treated and untreated pellets showed that the samples treated with Liberase TL had 3.3-fold more intact DNA than the untreated pellets.

Table 2 DNA recovered from B. burgdorferi B3I grown in BSK-H containing collagen coated slides after 28 days. Liberase concentrations ranged from 0.25 $\mathrm{U} / \mathrm{mL}$ to $\mathrm{IU} / \mathrm{mL}$. Times intervals were $\mathrm{I}, 4$ and 8 minutes

\begin{tabular}{lll}
\hline $\begin{array}{l}\text { Liberase } \\
\text { conc } \mathbf{U} / \mathbf{m L}\end{array}$ & $\begin{array}{l}\text { Treatment time } \\
\text { minutes }\end{array}$ & $\begin{array}{l}\text { DNA ng/uL from } \\
\text { each slide }\end{array}$ \\
\hline 0 & $\mathrm{I}$ & 3.4 \\
0.25 & $\mathrm{I}$ & 2.2 \\
0.5 & $\mathrm{I}$ & 0.6 \\
0.75 & $\mathrm{I}$ & 2.8 \\
$\mathrm{I}$ & $\mathrm{I}$ & 4.4 \\
0 & 4 & 1.4 \\
0.25 & 4 & 4 \\
0.5 & 4 & 0.9 \\
0.75 & 4 & 2.8 \\
$\mathrm{I}$ & 4 & 0.1 \\
0 & 8 & 0.6 \\
0.25 & 8 & 2.3 \\
0.5 & 8 & 2.5 \\
0.75 & 8 & 3 \\
\hline & 8 & 3.7 \\
\hline
\end{tabular}

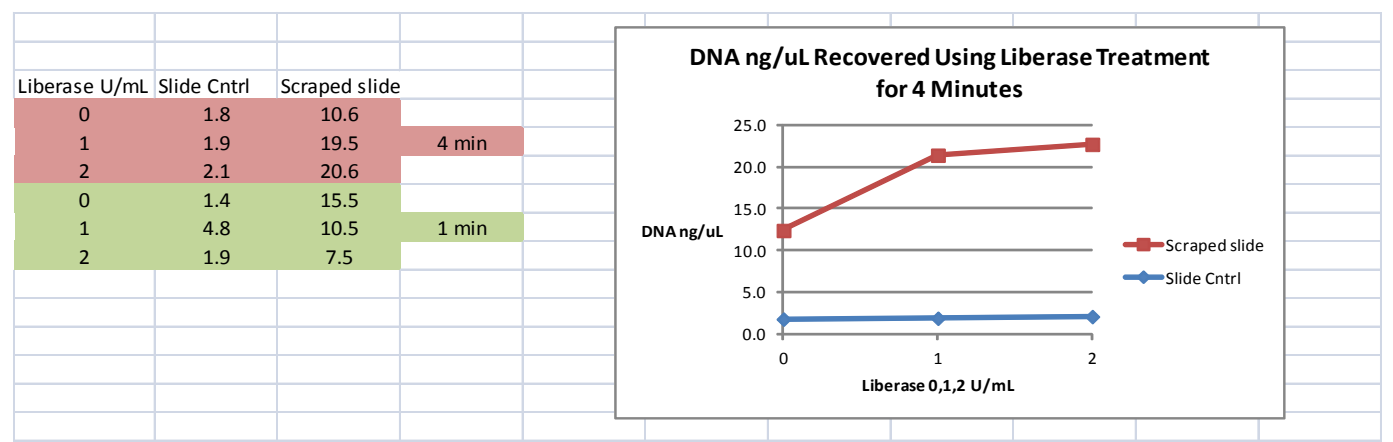

Figure 2 B. burgdorferi N40 DNA harvested from BSK-H cultures containing collagen-coated slides. Concentrations of $0, \mathrm{I}$, and $2 \mathrm{U} / \mathrm{mL}$; times of I and 4 minutes. 
Removal of human DNA: Controls for the Oxgall treatment for removal of human DNA showed that at all concentrations of Oxgall, $1.0 \%, 1.5 \%, 2.0 \%, 5.0 \%$, and $10 \%$, approximately $1.5 \times 10^{7}$ long spirochete forms were recovered (data not shown) showing that Oxgall could be used to remove human DNA with optimal Borrelia cells remaining.

Purification of the DNA: Purification using the Magnetic Bead technology MagJet kit yielded optimal concentrations of DNA on both Liberase treated and Liberase untreated samples.

\section{Amounts of DNA recovered from liberase treated and untreated samples}

The amounts of DNA obtained from untreated samples ranged from 2.9 to $5.6 \mathrm{ng} / \mathrm{uL}$ whereas the amounts of DNA recovered from Liberase treated samples ranged from 7.2 to $30.7 \mathrm{ng} / \mathrm{uL}$. The purity of the DNA from these samples was also higher as they showed less contamination with protein (Table 3 and Figure 3). Ratios of 260nm / 280nm, (DNA / impurities), were obtained. Ratios closer to 2.0 indicate high purity of DNA with little protein content. Ratios in the untreated samples ranged from 1.03 to 1.89 whereas ratios in the treated samples ranged from 1.74 to 2.03 .

Table 3 Comparison of 24 patient samples from culture treated with Liberase during harvesting and 24 patient samples from culture not treated with Liberase during the harvesting process. Following Liberase treatment of the pellets, samples were treated for the removal of human DNA (Zhou and Pollard, 20I2). The remaining Borrelia DNA was then extracted and purified using the Magjet Genomic DNA Kit. (Thermo Fisher Scientific).The resultant DNA was analyzed using the Nanodrop 2000 and ratios of 260/280 were obtained; $260 \mathrm{~nm}$ for DNA, $280 \mathrm{~nm}$ for impurities such as protein

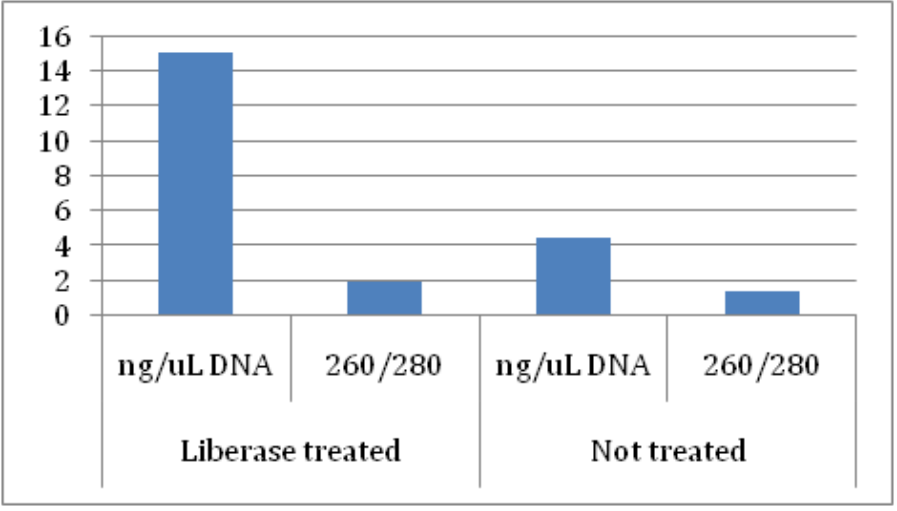

Figure 3 Average DNA yields and purity of pellets treated with Liberase versus pellets not treated with Liberase. DNA was analyzed using the Nanodrop 2000 and ratios of 260/280 were obtained; $260 \mathrm{~nm}$ for DNA, 280 $\mathrm{nm}$ for impurities such as protein.

Liberase treated (ng/uL): DNA - 15;260/280 - 1.95

Not treated (ng/uL): DNA - 4.5;260/280 - I.4

\begin{tabular}{|c|c|c|c|c|c|c|c|}
\hline \multicolumn{4}{|c|}{ Not treated with Liberase } & \multicolumn{4}{|c|}{ Treated with Liberase } \\
\hline Lab \# & Study \# & ng/uL & $260 / 280$ & Lab \# & Study \# & ng/uL & $260 / 280$ \\
\hline 5260 & $8 M S I$ & 4.8 & 1.89 & 5338 & $8 M S 49$ & 15.6 & 1.98 \\
\hline 5261 & $8 M S 2$ & 4.8 & 1.66 & 5339 & $8 M S 50$ & 15.9 & 1.9 \\
\hline 5263 & $8 M S 3$ & 4.6 & 1.64 & 5279 & $8 M S 5 I$ & 30.7 & 1.74 \\
\hline 5264 & $8 M S 4$ & 5.4 & 1.32 & 5299 & $8 M S 52$ & 16.3 & 2.03 \\
\hline 5265 & $8 M S 5$ & 6.3 & 1.63 & 5397 & $8 M S 53$ & 16 & 1.93 \\
\hline 5266 & $8 M S 6$ & 7.7 & 1.37 & 5398 & $8 M S 54$ & 14.1 & 1.88 \\
\hline 5269 & 8MS7 & 5.6 & 1.48 & 5399 & $8 M S 55$ & 17.8 & 1.95 \\
\hline 5270 & $8 \mathrm{MS} 8$ & 5 & 1.83 & 5400 & $8 M S 56$ & 16.6 & 2.02 \\
\hline 5273 & $8 M S 9$ & 5.6 & 1.45 & 5401 & $8 M S 57$ & 20.7 & 1.82 \\
\hline 5277 & $8 \mathrm{MSIO}$ & 5 & 1.52 & 5404 & $8 M S 58$ & 24.4 & 1.81 \\
\hline 5278 & $8 M S I I$ & 5.1 & 1.5 & 5408 & $8 M S 59$ & 18 & 1.88 \\
\hline 5280 & $8 M S I 2$ & 4.7 & 1.81 & 5409 & $8 M S 60$ & 15.6 & 2.2 \\
\hline 5282 & $8 \mathrm{MSI} 3$ & 3.1 & 1.18 & 5340 & $8 M S 6 I$ & 14.2 & 2.3 \\
\hline 5283 & $9 M S I 4$ & 3.8 & 1.45 & 5341 & $8 M S 62$ & 11.9 & 1.92 \\
\hline 5284 & $8 M S I 5$ & 4.4 & 1.33 & 5342 & $8 M S 63$ & 10.9 & 2.1 \\
\hline 5285 & $8 M S 16$ & 3.3 & 1.28 & 5343 & $8 M S 64$ & 13.7 & 1.96 \\
\hline 5287 & $8 M S I 7$ & 4.2 & 1.41 & 5345 & $8 M S 65$ & 14.6 & 1.96 \\
\hline 5289 & $8 M S I 8$ & 3.1 & 1.63 & 5349 & $8 M S 66$ & 13.2 & 1.87 \\
\hline 5290 & $8 M S I 9$ & 3.4 & I.II & 5350 & $8 M S 67$ & 9.4 & 2.03 \\
\hline 5295 & $8 M S 20$ & 2.9 & 1.27 & 5351 & $8 M S 68$ & 9.4 & 1.97 \\
\hline 5296 & $8 M S 21$ & 4.1 & 1.18 & 5358 & $8 M S 69$ & 15.7 & 1.88 \\
\hline 5299 & $8 M S 22$ & 3.6 & 1.17 & 5359 & $8 M S 70$ & 11.5 & 1.76 \\
\hline 5300 & $8 M S 23$ & 3.6 & 1.45 & 5360 & 8MS7I & 11.2 & 1.87 \\
\hline 5302 & $8 M S 24$ & 3 & 1.03 & 5366 & $8 M S 73$ & 7.2 & 2.04 \\
\hline Average & & 4.46 & $\mathrm{I} .44$ & & & 15.19 & 1.95 \\
\hline
\end{tabular}




\section{Discussion}

Often it is assumed that primary virulence factors of microbes are genetically controlled in response to their immediate environment In experiments using Vibrio cholerae, Anjali et al., ${ }^{11}$ showed that the regulation of virulence factors occurs in the body and is very different from genetic regulation in laboratory media. Pathogens adapt to the host environment by altering their gene expression. Using RNA sequence based transcriptome analysis of V. cholerae during infection in rabbits and mice, data was obtained for the recognition of regulatory response during infection. Genes and small RNAs were discovered that previously had not been linked to virulence. These studies clarified the need to examine genetic regulation in response to an internal mammalian system rather that just from studies performed in the laboratory.

DeRita et al., ${ }^{12}$ contrasted the complex regulatory pathway in $V$. cholerae that evolved to control virulence by induction of gene expression in vivo with that of Streptococcus pyogenes that exhibits at least one mode of pathogenesis that manifests in the absence of regulation. Both organisms respond to their environment in differing adaptive ways. Additionally, Moreira et al., ${ }^{13}$ elucidated the effects of a global regulator, QseC, in Salmonella enterica serovar typimurium, which regulates genes within pathogenesis islands I and II both in vitro and in vivo. Bent et al., ${ }^{14}$ showed that the chromosomally encoded Ysa T3SS in Yersinia enterocolitica is expressed in a contact dependent manner in vitro and is also expressed in vivo during infection in mice. The differing strategies used by organisms to survive and thrive in their environments reflect evolutionary adaptation and contribute to pathogenesis.

The production of adhesins by Borrelia occurs in certain types of media but not others. Studies have shown the presence or absence of BBK32, an adhesion that allows the organism to attach to fibronectin, depending on the growth media and conditions that the organism is experiencing in its immediate environment. ${ }^{15,16}$ Two adhesins that Borrelia produces for attachment to collagen have recently been elucidated, CspA and CspZ. ${ }^{17}$ These outer surface glycoproteins may influence the migration and sequestration of the organism in the human body. Although investigators defend differing positions as to the presence or absence of such factors and whether or not they constitute virulence factors, it is clear that migration through tissue in the human body can be aided by attachment to and then penetration of tissue. If the organism did not have a way to anchor itself to the ECM, vascular epithelium, and/or other components within the blood that wash the tissue, then its ability to sequester and survive in the niches of the human body would not lead to chronic infection and evasion of the immune system. Taking these assumptions into consideration, the demonstration of and the exploitation of the organism's survival mechanisms has greatly facilitated our ability to grow and harvest Borrelia that has attached to collagen in vitro.

Borrelia and its interaction with interstitial components of the mammalian body have led investigators to incorporate some of these components into in vitro cultivation methodology. ${ }^{1,4}$ One of the most studied means of attachment is the interaction of Borrelia with collagen, both in vivo and in vitro. ${ }^{2}$ Two of the known adhesins that Borrelia uses to bind collagen include CspA and CspZ. ${ }^{13}$ Although they are recognized as adhesins, the molecular regulation of their production has not been studied in cultures of human blood, so it is not known if their production is down regulated or up regulated in blood culture. Nevertheless, the ability of the organism to thrive in culture and interact with collagen becomes evident in our study of the present methodology.

Our improved method for harvesting Borrelia results in the recovery of higher concentrations of DNA. The organisms attachment to, and growth in, the collagen matrix in culture is used to our advantage in the new harvesting procedure. Their release from the collagen, after incubation with Liberase, results in our ability to harvest more biomass, and thus more DNA. In addition, the DNA obtained is less contaminated with residual protein.

\section{Conclusion}

Our laboratory was able to increase the concentration and purity of Borrelia DNA harvested from culture pellets by using an enzyme preparation capable of breaking bonds within the collagen matrix and also between Borrelia and collagen. The preparation, Liberase $\mathrm{TL}$, is composed of collagenases and neutral proteases. The release of Borrelia from the collagen matrix by the enzyme preparation was concentration and time dependent. Optimal enzymatic treatment conditions yielded 3.3-fold more DNA. The DNA isolated had higher purity with less residual protein than that harvested from untreated pellets.

\section{Acknowledgments}

None.

\section{Conflicts of interest}

Authors declare that there is no conflict of interest.

\section{References}

1. Wainwright INM. Lichen removal from an engraved memorial to Walt Whitman. Association for preservation Technology Bulletin. 1986;18(4):46-51.

2. Griffin PS, Indicator N, Koestler RJ. The biodeterioration of stone: A Review of deterioration mechanisms, conservation case histories and treatment. International Biodeterioration. 1991;28(1-4):187-207.

3. Rebricova NI. Some ecological aspects of protection of Old Russian paintings from microbiological deterioration. Proceedings of the International conference on biodeterioration of cultural property: India; 1989. 294-306 p

4. Xie W. Identification and Preservation of mould on the frescoes from Chinese Tong tomb. Proceeding of the EEC China workshop on preservation of cultural heritage: China; 1992. 431-438 p.

5. Gorbushina AA, Krumbein WE, Hamman $\mathrm{CH}$, et al. Role of black fungi on color change and biodeterioration of antique marbles. Taylor \& Francis CRC Press: Spain; 1993. 205-221 p.

6. Koyano M. Fungal contamination of Japanese painting stored in Japan. Proceedings of the $2^{\text {nd }}$ International Conference, Biodeterioration of Cultural property: Japan; 1993. 570-581 p.

7. Arai H. Foxing caused by fungi. Twenty five years of study. International Biodeterioration \& Biodegradation. 2000;46(3):181-188.

8. Strzelczyk AB. Observation on aesthetic and structural changes induced in Polish historic objects by microorganisms. International Biodeterioration \& Biodegradation. 2004;53(3):151-156.

9. Juroczkin J, Bode K, Petersen K, et al. Some physiological characteristics of fungi isolated from sandstone. Proceedings of the $5^{\text {th }}$ International Congress on Deterioration and Conservation of Stone: Poland; 1988. 21-25 p. 
10. Petersen K, Grote G, Krumbein WE. Biotransfer of metals by fung isolated from rock. In: Proceedings of the $5^{\text {th }}$ International Congress on Deterioration and Conservation of stone: Poland; 1988a. 111-119 p.

11. Maria PDB, Maddalena DG, Paola C, et al. Microbial formation of oxalate films on monuments surface: Bioprotection or biodeterioration. Geomicrobiology Journal. 1999;16(1):55-64.

12. Martino E, Pandi L, Fenoglio I, et al. Soil fungal hyphae bind and attack asbestos fibers. Angew Chem Int Ed Engl. 2003;42(2):219-222.

13. Garcia-Valles M, Urzi C, De Leo F, et al. Biological weathering and mineral deposits of the Belevi marble quarry (Ephesus, Turkey) International Biodeterioration \& Biodegradation. 2000;46(3):221-227.

14. De-la-Torre MA, Gomez Alarcon G, Vazcaino C, et al. Biochemical mechanisms of stone alteration carried out by filamentous fungi living in monuments. Biogeochemistry. 1993;19:129-147.

15. Saiz-Jimenez C. Microbial melanins in stone monuments. Science of the Total Environment. 1995;167(1-3):273-286.

16. Hirsch P, Eckhardt FEW, Palmer RJJ. Fungi active in weathering of rock and stone monuments. Canadian Journal of Botany. 1995;73(S1):1384-1390

17. Diakumaku E, Ausset P, Sterflinger K, et al. On the problem of rock blackening by fly ash, fungal and other biogenic particles and their detection in Mediterranean marbles and monuments. Proceedings of the $3^{\text {rd }}$ International Symposium: Italy; 1994. 305-310 p.

18. Cooke WB. A laboratory guide to fungi in polluted waters, sewage, and sewage treatment systems; their identification and culture. Public Health Service: Cincinnati, USA; 1963.
19. Nilson S. Atlas of Airborne fungal spores in Europe. Springer-Verlog: Germany; 1983.

20. Lopez FF, Gomez EF. Simultaneous determination of the major organic acids, sugars, glycol and ethanol by HPLC in Grape musts and white wines. Journal of Chromatographic Science. 1996;34(5):254-257.

21. Kigwa R, Arai H. Identification report. Filamentous fungi isolated from various kinds of materials of cultural property. Science for conservation. $1995 ; 34: 8-12$

22. Kwsana H. Mukoflora wystepujaea nazaprawie gipsowej ruin zespolu palacowego Wlednigorze. Ochrona Zabytkov. 1995;48:97-100.

23. Sterflinger K. Fungi as geologic agents. Geomicrobiology Journal. 2000;17:97-124.

24. Tiano P. Biodeterioration of Monumental rocks: decay mechanisms and control methods. Science and technology for cultural heritage. 1998;7(2):19-38.

25. Monte M. Oxalate film formation on marble specimen caused by fungus. Journal of Cultural Heritage. 2003;4(3):255-258.

26. Wilson MJ, Jones D, McHardy WJ. The weathering of serpentinite by Lecanora atra. Lichenologist. 1981;13(2):167-176.

27. Bruand A, Duval O. Calcified fungal filaments in the petrocalcic horizon of Eutrochreptsin Beavce, France. Soil Science Society of America Journal. 1999;63:164-169. 